\title{
Produção do espaço no eixo sul do aglomerado urbano de Macapá e Santana na Amazônia setentrional amapaense
}

\author{
Romário Valente Santos ${ }^{1}$ e Elcimar de Sousa Barros ${ }^{2}$
}

\begin{abstract}
1 Mestre em Desenvolvimento Regional (UNIFAP), Especialista em Metodologia do Ensino de Geografia (EAP-GEA) e Graduado em Geografia (UFPA). Professor da Secretaria Estadual de Educação do Amapá, Brasil. E-mail: romario_geo@yahoo.com.br; romariomdrgeo@gmail.com

2 Especialista em Educação de Jovens e Adultos (IFAP) e Graduado em Ciências Ambientais (UFPA), Brasil. E-mail: barrossitb2008@hotmail.com
\end{abstract}

RESUMO: O Aglomerado Urbano de Macapá e Santana (AUMS), localizado na Amazônia Setentrional Amapaense (ASA), é estruturado em eixos e centros urbanos: Eixo Norte, Eixo Oeste, Eixo Sul, Centro Urbano de Macapá e Centro Urbano de Santana. Todas estas frações do espaço urbano do AUMS possuem dinâmicas próprias e simultaneamente se (des)encontram na produção social desse espaço urbano. Destes Eixos, a porção Sul possui um processo de valorização espacial e diferenciação socioespacial mais significativo em relação às demais fração, considerando os padrões dos produtos imobiliários existentes e o preço dos lotes/terrenos, por isso o presente artigo tem como objetivo analisar a produção do espaço neste Eixo Sul, para isso a metodologia utilizada foi organizada da seguinte forma: revisão bibliográfica de obras de referência sobre a temática da produção do espaço, bem como os trabalhos de Santos (2016), Amaral (2010) e Santos (2012); análise documental dos Planos de Desenvolvimento Urbano produzidos para Macapá e da legislação sobre ressacas e uso do solo nesta cidade; compreensão sobre o marketing urbano neste eixo.

Palavras-Chave: Produção do Espaço, Aglomerado Urbano de Macapá e Santana, Amazônia Setentrional Amapaense, Processos Socioespaciais, Planos de Desenvolvimento Urbano.

\section{Space production in axis south axis of aglomerate urban Macapá and Santana and the Amazon northern of Amapa}

ABSTRACT: The Aglomerate Urban Macapá and Santana (AUMS) located in the northern Amazon of Amapa (ASA), is structured in Axes and Urban Centers: North Shaft, West Axis, South Axis, Macapa Urban Center and Santana Urban Center. All these fractions Urban AUMS space have their own dynamics and simultaneously (un) are in the social production of this urban space. These axes, the south portion possess a space recovery process and more significant socio-spatial differentiation in relation to the other fraction, considering the standards of the existing real estate products and the price of lots / land, so this article aims to analyze the production of space in the South Axis, for that the methodology used was organized as follows: literature review of reference works on the topic of production space, as well as the works of Santos (2016), Amaral (2010) and Santos (2012); documental analysis of the Urban Development Plans produced to Macapa and legislation on hangovers and land use in the city; conducting fieldwork and semi-structured interviews with collection points for the preparation of cartographic material and survey material on urban marketing this axis.

Keywords: Production Space, Aglomerate Urban Macapá and Santana, Northern Amazon Amapaense, socio-spatial processes, Urban Development Plans.

\section{INTRODUÇÃO}

O Aglomerado Urbano de Macapá e San-
tana (AUMS), localizado na Amazônia Se- tentrional Amapaense ${ }^{1}$ (ASA) (Mapa 01) é a

${ }^{1} \mathrm{~A}$ área core dessa sub-região amazônica é constituído pelo território do Estado do Amapá, além de porções de territórios de alguns municípios do Estado do Pará e do Departamento Ultramarino Francês - DOM (Département d'Outre-mer), a Guiana Francesa. Assim, destaca-se que essa sub-região não coincide com o recorte 
materialização da dinâmica e da centralidade urbana e regional exercida pelas principais cidades da desta Sub-Região Amazônica formada pelo estado do Amapá e as ilhas do Golfão Marajoara no Pará.

Mapa 01: Centralidade Urbana sub-regional do Aglomerado Urbano de Macapá e Santana na Amazônia Setentrional Amapaense.

Map 01: Sub-regional Urban Centralization of the Macapá and Santana Urban Agglomerate in the Northern Amazonia Amapaense.

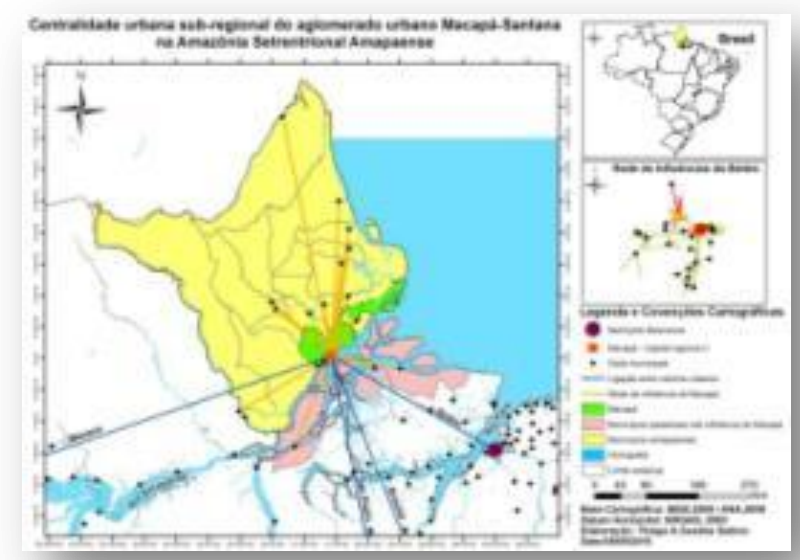

Fonte: Santos, 2016.

Macapá possui sua formação socioespacial vinculada à construção da Fortaleza de São José, em 1758, no período da colonização portuguesa na Amazônia, quando ainda era vila, assim como Santana, que no mesmo período era conhecida como Vila de Sant'Ana. Até 1987, quando foi elevada à condição de município, Santana era distrito de Macapá, durante sua condição de distrito, Santana passou por um processo de urbanização mais significativo com o início das atividades da Indústria de Mineração e Co-

territorial do estado do Amapá, mas extrapola o limite administrativo estadual e nacional, abrangendo áreas dos municípios paraenses de Almeirim, Chaves, Afuá e Gurupá e se sobrepõe de forma reticular ao território da Guiana Francesa, através do eixo de migração internacional de brasileiros, principalmente, para as cidades de Saint Georges, Cayenne e Kourou (SANTOS, 2012). mércio (ICOMI) a partir da década de 1950, justamente quando foram construídas infraestruturas como suporte às atividades de mineração desenvolvidas em Serra do Navio, também distrito de Macapá na época.

O porto de exportação do manganês extraído em Serra do Navio, a construção da Estrada de Ferro do Amapá (EFA), ligando o espaço de extração ao porto, a construção da Vila Amazona, cidade planejada para abrigar parte da mãe de obra da ICOMI, o escritório da empresa situado entre o porto e a EFA, enfim, uma série de infraestruturas foram construídas e, juntamente com outras atividades implantadas em Macapá e Santana, fizeram destas as principais cidades da porção mais setentrional da região amazônica, chamada por Santos (2012) de Amazônia Setentrional Amapaense (ASA).

Macapá e Santana tornaram-se as principais bases logísticas dos grandes projetos desenvolvidos na ASA (SANTOS, 2011). Por isso ganharam destaque tanto na escala local, quanto noutras escalas. A partir daí, pode-se afirmar a gradativa formação de um aglomerado urbano embasado na dinâmica urbana única entre as cidades, tendo como referência as complementaridades urbanas (Quadro 01) existentes.

Quadro 01: Complementaridade urbana entre Macapá e Santana a partir dos sistemas de objetos e sistemas de ações.

Frame 01: Urban Complementarity between Macapá and Santana from the systems of objects and systems of actions.

\begin{tabular}{|c|c|c|}
\hline Cidade & Sistema de objetos & Sistema de ações \\
\hline SANTANA & $\begin{array}{l}\text { - Porto de Santana } \\
\text { - Estrada de Ferro } \\
\text { - Vila Amazonas } \\
\text { - Porto do Grego } \\
\text { - Distrito Industrial } \\
\text { de Santana }\end{array}$ & $\begin{array}{l}\text { - Exportação do manganês } \\
\text { extraído na Serra do Navio } \\
\text { - Liga o espaço de extração } \\
\text { mineral em Serra do Navio } \\
\text { ao Porto de Santana } \\
\text { - Vila operária dotada de } \\
\text { plano urbanístico para } \\
\text { abrigar mão de obra da } \\
\text { ICOMI e que com o fim das } \\
\text { atividades da empresa } \\
\text { passou por um processo de } \\
\text { refuncionalização assumin- }\end{array}$ \\
\hline
\end{tabular}




\begin{tabular}{|c|c|c|}
\hline & & $\begin{array}{l}\text { do o papel de abrigar parte } \\
\text { da elite econômica e políti- } \\
\text { ca de Santana } \\
\text { - Porto privado de onde } \\
\text { chegam e partem fluxos de } \\
\text { pessoas, mercadorias, } \\
\text { capitais e serviços de al- } \\
\text { gumas regiões da Amazô- } \\
\text { nia, principalmente de } \\
\text { Belém } \\
\text { - Criado para estimular as } \\
\text { atividades industriais em } \\
\text { Macapá, este distrito in- } \\
\text { dustrial que hoje pertence } \\
\text { a Santana, acabou tornan- } \\
\text { do-se o ponto de encontro } \\
\text { de um sistema modal de } \\
\text { logística entre Belém e o } \\
\text { AUMS }\end{array}$ \\
\hline MACAPÁ & $\begin{array}{l}\text { - BR } 156 \text { e BR } 210 \\
\text { - Aeroporto } \\
\text { - Aterro controlado } \\
\text { que atende Macapá } \\
\text { e Santana } \\
\text { - Terminal Rodoviá- } \\
\text { rio de onde partem } \\
\text { ônibus para várias } \\
\text { cidades do estado. } \\
\text { - Portos (Igarapé } \\
\text { das mulheres, } \\
\text { Igarapé das Pe- } \\
\text { drinhas, Igarapé do } \\
\text { Jandiá e Igarapé da } \\
\text { Fortaleza) }\end{array}$ & $\begin{array}{l}\text { - Rodovias que articulam } \\
\text { Macapá com o restante do } \\
\text { estado } \\
\text { - Atende a demanda de } \\
\text { toda a ASA } \\
\text { - Utilizado provisoriamente } \\
\text { pelas cidades de Macapá e } \\
\text { Santana } \\
\text { - Portos que atendem a } \\
\text { vários municípios da ASA e } \\
\text { também articulam com } \\
\text { cidades paraenses como } \\
\text { Abaetetuba }\end{array}$ \\
\hline
\end{tabular}

Fonte: Santos, 2015.

Percebe-se, então, o compartilhamento de objetos e ações entre Macapá e Santana. É isto que dá base a existência do AUMS. Neste processo histórico de articulação entre as duas cidades, é cada vez maior a relação entre ambas nos termos do espaço absoluto, relativo e relacional ou se preferir, na urbanização da população, da sociedade e do território.

Santos (2016) afirma, além da formação do AUMS, estar em curso neste aglomerado urbano um processo de reestruturação urbana resultante da nova expansão capitalista na Amazônia, onde, dentre outros elementos, tem-se disseminado novos produtos imobiliários da habitação no interior das cidades amazônicas, portanto não mais de maneira restrita aos centros metropolitanos como noutros recortes temporais.

Objetivando compreender melhor este processo de reestruturação urbana, Santos (2016) propõe uma forma de compreensão do AUMS pautada em três eixos que acompanham rodovias estaduais e federais localizadas direta e indiretamente entre Macapá e Santana, além de dois Centros Urbanos mais zonais, configurados como adensamentos populacionais principais e "nós" de articulação dos eixos interurbanos.

A estruturação urbana de Macapá e Santana em Centros Urbanos e Eixos revela a forma como tem se dado a relação historicamente construída entre as duas cidades e seus rebatimentos no espaço intraurbano, através dos processos espaciais específicos. Desta forma, observa-se a seguinte estruturação: Centro Urbano de Macapá, Centro Urbano de Santana, Eixo Sul, Eixo Oeste e Eixo Norte.

O Centro Urbano de Macapá destaca-se por ser a principal porção do AUMS, isso por que é neste centro urbano que se localiza o setor principal de comércio e serviços que recebe consumidores e usuários das duas cidades, além da gestão pública municipal e estadual. Neste centro urbano o crescimento vertical vem ganhando cada vez mais destaque, principalmente a partir de 2010 quando as alterações no Plano Diretor de Desenvolvimento Urbano e Ambiental de Macapá (PDDUAM) liberaram a construção de um número maior de pavimentos em algumas áreas deste centro urbano.

O Centro Urbano de Santana, que se liga com o Centro Urbano de Macapá através das rodovias AP - 010 e AP - 020, apresenta sua dinâmica muito ligada as atividades da 
exportação de minérios, estagnada nos últimos 2 anos e meio, portanto à lógica da atividade portuária. Ao longo da Orla Fluvial deste centro urbano, há os seguintes portos: porto do Igarapé da Fortaleza, porto da CDSA, porto Souzamar, porto das Catraias ${ }^{2}$, porto do Grego, porto Municipal, porto da mineradora Anglo e os portos das empresas de logística instalados no Distrito Industrial de Santana. Estes elementos revelam que boa parte das relações da cidade se dá através do rio, além disso, destaca-se a modernização deste centro urbano com a criação de novas formas espaciais do comércio e dos serviços, principalmente na forma de franquias, reformulando o próprio conteúdo da urbanização.

Foram, também, definidos três eixos de estruturação urbana, dois deles ligam diretamente Macapá à Santana (Eixos Sul e Oeste) e outro liga indiretamente (Eixo Norte). Por estes três eixos é cada vez maior o número de novos produtos imobiliários da habitação e do comércio e serviços, todavia esse processo tem se dado de maneiras distintas.

No Eixo Norte, os loteamentos são os produtos imobiliários da habitação mais comercializados e a preços bem mais conta do que nos outros Eixos, destinados principalmente a um público com faixa de renda a partir de dois salários mínimos. Neste eixo também se destaca a presença marcante do conjunto Macapaba, um produto imobiliário público construído dentro do Programa Minha Casa Minha Vida (PMCMV) do Governo Federal.

\footnotetext{
${ }^{2}$ Catraia é o nome dado a um tipo de embarcação local, movida a motor, bastante utilizado para realizar o transporte de passageiros ao longo do rio Matapi, principalmente entre o Distrito de llha de Santana e a sede municipal.
}

No Eixo Sul predominam produtos imobiliários de alto padrão com terrenos inclusive no valor de um milhão de reais como no empreendimento Verana Macapá, isto se explica, dentre outros elementos, pelo fato da disponibilidade de terrenos ser menor do que nos outros eixos, pois as margens da Rodovia AP - 010 são imprensadas de um lado pelo rio Amazonas e pelo outro por várias áreas de ressacas, daí a o alto preço dos terrenos e a maior valorização espacial.

O Eixo Oeste possui um padrão misto, pois há produtos imobiliários de alto, médio e baixo padrão. Há empreendimentos do porte do Eixo Sul, destinado a um público com maior poder aquisitivo, e do Eixo Norte, destinados a um público com faixas de renda a partir de dois salários mínimos.

Paralelamente a difusão de novos produtos imobiliários da habitação, o setor de comércios e serviços tem se expandido em direção aos eixos de estruturação urbana apresentada, além de se modernizar nos centros urbanos de Macapá e Santana. Novas franquias, expansões, modernizações de prédios antigos são cada vez mais verificadas na paisagem urbana do AUMS, revelando novas centralidades intra e interurbanas.

Diante deste quadro geral da estruturação urbana de Macapá e Santana, será discutido neste trabalho especificamente o Eixo Sul, tendo em vista ser este o setor do AUMS em que se observa maior presença do processo de valorização espacial, o qual se vincula ao processo de reestruturação urbana, que representa as transformações urbanas destas duas cidades da ASA, tanto na escala da relação entre ambas, quanto no próprio papel desempenhado, articuladamente, por elas para toda esta sub-região Amazônica. 
2 A CONSTRUÇÃO HISTÓRICA DO EIXO SUL DE MACAPÁ

O Eixo Sul de Macapá expressa parte deste processo de descentralização da produção do espaço urbano da cidade de Macapá, presente em sua própria formação socioespacial. Pautado nisso, vale realizar um breve resgate histórico para se compreender a forma como ocorreu este processo que hoje ganha novos contornos, para isso vale analisar o que foi pensado nos planos diretores produzidos para Macapá e Santana.

Macapá e Santana tiveram suas ocupações realizadas em seus Centros Urbanos, especificamente na porção mais próxima ao rio Amazonas, muito ligadas à dinâmica do rio, que até hoje é um grande referencial material e simbólico para as populações residentes nestas cidades amazônicas. Todavia, Gonçalves (2001) chama atenção para a mudança no padrão de organização espacial da região de rio-várzea-floresta para estrada-terra-firme-subsolo.

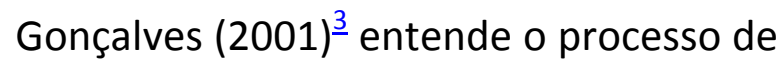
urbanização regional a partir de dois momentos, identificados como padrões de organização do espaço. Um primeiro padrão nomeado de rio-várzea-floresta, hegemônico até a década de 1950 e outro identificado como estrada-terra-firme-subsolo, marcado pela implantação da rodovia BelémBrasília, a partir da década de 1950. No primeiro padrão houve expressiva importância do extrativismo enquanto atividade

\footnotetext{
${ }^{3}$ Gonçalves (2001) aponta os padrões rio-várzea-floresta e estrada-terra-firme-subsolo como padrões reveladores do circuito espacial da produção nos diferentes momentos da rede urbana regional, portanto ele evidencia os espaços da produção, da circulação e do consumo.
}

econômica predominante na região, ao passo que no segundo padrão são mais expressivos a agricultura e a pecuária, além da atividade da mineração ${ }^{4}$.

No contexto da Amazônia Setentrional não ocorreu de forma diferente, até porque o projeto de mineração em Serra do Navio foi pioneiro. Foi justamente a partir desta política de ocupação projetada pelo governo militar para a Amazônia, que as rodovias foram implantadas nessa porção mais setentrional da região, mesmo se tratando de faixas rodoviárias mais intraurbana, deve-se considerar seu potencial de vetor de ocupação consagrado pelas ações do Estado, do mercado imobiliário ou dos grupos sociais excluídos.

Neste período da política de construção de rodovias na Amazônia, alguns planos diretores foram formulados para a cidade de Macapá ou para todo o Território Federal do Amapá. Estes planos projetaram uma produção do espaço cada vez mais periférica, revelada atualmente na difusão de processos espaciais como a descentralização, a conurbação e a consequente formação de novas centralidades intra e até interurbanas, dependendo do grau de articulação dos empreendimentos existentes.

O Plano Urbanístico da Cidade de Macapá/Relatório Grumbilf do Brasil (PUCMRGB), de 1960, não faz uma análise sobre a articulação com Santana, destacando inclusive que a cidade de Macapá encontravase isolada em relação a outros centros ur-

${ }^{4}$ Os padrões apresentados por Gonçalves (2001) não revelam de maneira total a forma como aconteceu o processo de ocupação regional, por isso, Miranda (2009) afirma existirem outros referenciais empíricos que devem ser considerados, como as estradas de ferro existentes no interior da região, as quais constituíramse como vetores de ocupação e surgimento de núcleos urbanos. 
banos mais populosos, limitando-se a citar a existência da rodovia Macapá-Porto Santana como espaço de ligação com a Área Industrial e como parte da infraestrutura existente na cidade de Macapá, feita através de um breve inventário presente neste plano. Portanto, não houve um esforço de entendimento das articulações entre Macapá e Santana, principalmente em relação ao seu Eixo Sul (Mapa 02), apesar das atividades da ICOMI já desenharem fortes relações entre as cidades.

Mapa 02: Eixo Sul de Macapá na década de 1970.

Map 02: South axis of Macapá in the 1970s.

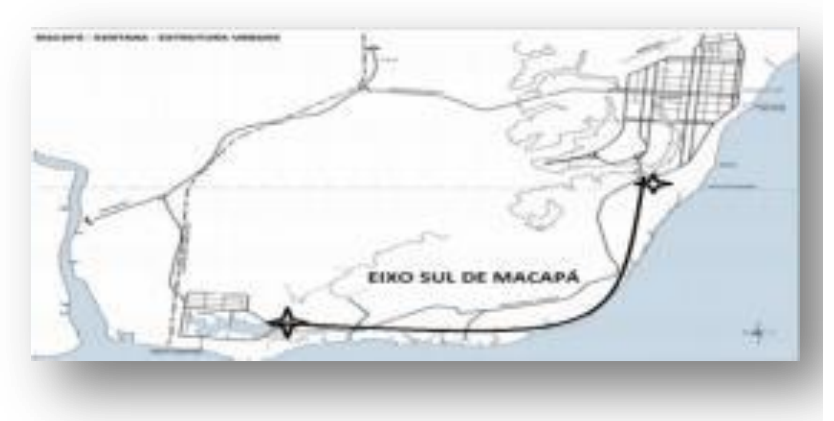

Fonte: Adaptado de Portilho, 2006.

Mesmo secundarizando a rodovia entre Macapá e Santana (atual Rodovia Duca Serra), o PUCMRGB falava da possibilidade, apesar de prematura na época, de se construir uma estação ferroviária, diante da evolução de Macapá, dos significativos volumes de carga e passageiros. Isto foi garantido através da reserva de áreas para construção da estação que ligaria Macapá e Santana, assim, "provavelmente haverá também uma colonização cada vez maior ao longo da ferrovia, e em consequência, um crescimento considerável da população" (PUCMRGB, 1960, p.46).

Outro ponto relatado foi uma possível descentralização ${ }^{5}$, muito embora tenha sido

\footnotetext{
${ }^{5}$ Em relação aos serviços de saúde, por exemplo, já havia
}

superficialmente descrito no PUCMRGB. Em relação a este processo deve-se destacar o fato dele ter sido mencionado num período em que a concentração demográfica e o uso do solo no centro de Macapá ainda não eram tão intensos. Nestes termos, o plano destaca que:

Em quasi tôdas (sic) as cidades notam-se tendências de descentralização. Assim, como o crescimento das cidades surgiu em cada bairro núcleos comerciais e de diversões próprios, descongestionando os centros já saturados de tráfego e consequente impossibilidade de estacionamento (PUCMRGB, 1960, p.55).

O Plano de Ação Imediata de Macapá (PAIM), publicado em 1971, trouxe, dentre outras ponderações, uma breve discussão entorno do crescimento no eixo da Rodovia Fazendinha (aqui tratada como Eixo Sul). Este plano tratava o crescimento deste eixo como tendência já evidenciada na concentração para além da "cadeia do Beirol" e ao mesmo tempo destacava a ressaca do Beirol como um obstáculo, que sendo superado daria acesso a um "terreno novamente alto e seco". Portanto o PAIM tocava num ponto importante, associava a dinâmica de ocupação com a base natural da cidade, já que Macapá e Santana são recortadas internamente por várias ressacas ${ }^{6}$.

\footnotetext{
uma preocupação clara de descentralização: Por sugestão do Chefe da Divisão de Saúde, Dr. Mário de Medeiros Barbosa, a assistência médica e hospitalar deverá futuramente ser descentralizada, criando-se centros de saúde, postos de puericultura, e prontos socorros distritais (PUCMRGB, 1960, p.19).

${ }^{6}$ Em Macapá e Santana as áreas úmidas recebem a atribuição local de "Ressacas", caracterizadas por serem "sistemas físicos fluviais colmatados, drenados por água doce e ligadas a um curso principal d'água, influenciados fortemente pela pluviosidade e possuindo vegetação herbácea" (TAKYAMA et al., 2012, p.9).
}

https://periodicos.unifap.br/index.php/estacao Macapá, v. 6, n. 3, p. 111-126, set./dez. 2016 
Embora não tenha avançado na discussão do crescimento da rodovia Fazendinha, o PAIM destaca o fato do adensamento da ocupação da cidade, no período da formulação e publicação do plano, estar diretamente ligado à transformação do cenário econômico local. Apontando ainda que o baixo poder aquisitivo e as facilidades para se obter lotes urbanos relativamente próximos não estimulou na época o surgimento de empreendimentos imobiliários de habitação coletiva (como os loteamentos e condomínio que cada vez mais marcam a paisagem urbana dos eixos de estruturação urbana de Macapá e Santana) ou na forma de escritórios que poderiam ser responsáveis por gerar o adensamento. Além disso, o plano também afirma haver uma população com costumes ruralistas ainda fortes, dificultando a implantação de empreendimentos imobiliários de uso coletivo.

Objetivando potencializar o uso do solo na cidade, o PAIM recomendou "exercer formal e efetivamente o planejamento e a coordenação na ocupação e no uso do solo urbano" (PAIM, 1971, p.177). Recomendouse, também, o controle da expansão urbana nas áreas de ressaca, neste sentido, havia toda uma preocupação em torno da importância destas áreas para a cidade e também da base natural de Macapá como elemento limitador das áreas lotáveis.

Analisada com mais atenção, em 1973, pelo Plano Diretor de Desenvolvimento Urbano da Fundação João Pinheiro (PDDUFJP) como rodovia de interligação, a AP - 010 (Rodovia Fazendinha/ Rodovia JK) é a principal indutora do processo de ocupação ocorrido no Eixo Sul da Macapá. Neste plano, o Eixo Sul de Macapá foi definido como Rodovia de Interligação no 2 e no 3 com as seguintes características:
RODOVIA DE INTERLIGAÇÃO no 2: A Rodovia de Interligação no 2 faz a ligação de Fazendinha com o entroncamento das Rodovias Macapá/Santana e BR-156, oferecendo melhor opção de acesso de Fazendinha ao restante do Território, além de ter função indutora de ocupação da área de produção hortigranjeira. RODOVIA DE INTERLIGAÇÃO no 3: A Rodovia de Interligação no3 liga Santana a Rodovia para Porto do Céu, passando, também, pelo interior da área prevista para produção hortigranjeira, constituindo-se em rodovia de indução, como as anteriores (PDDUFJP, 1973, p.28).

Duas questões ganham destaque a partir da proposta de rodovias de interligação: a primeira relacionada à definição de uma área de produção hortifrutigranjeira conhecida como Fazendinha. Segundo o PDDUFJP (1973), esta área foi pensada para auxiliar no abastecimento da cidade de Macapá e ao mesmo tempo atuar como indutora da ocupação desta porção da cidade, que na época possuía características predominantemente rurais. Este elemento hoje se reproduz como renda da terra, ou seja, transformação de terra rural em terra urbana, resultante na expansão do perímetro urbano da cidade. A segunda diz respeito à definição desta rodovia de interligação como zona de expansão urbana, previsão que está ocorrendo de maneira cada vez mais acelerada. Neste sentido, o PDDUFJP definiu o atual Eixo Sul, junto com os outros eixos de estruturação do espaço urbano de Macapá, como zonas de expansão urbana ${ }^{7}$.

\footnotetext{
${ }^{7}$ No zoneamento urbano apresentado pelo PDDUFJP as Zonas de Expansão Urbanas foram definidas como espaços disponíveis para responder ao adensamento populacional pra 85 habitantes por hectare a partir de 1968, por possuírem um preço mais baixo dos terrenos, estas áreas mostrar-se-iam bastante atrativas para a ocupação. Nestes termos, havia indícios da possibilidade do processo de descentralização, pois "a demanda 
O PDDUFJP (1973) afirmava ainda que a ocupação das zonas de expansão urbana era uma "tendência espontânea". Outro ponto destacado é a base natural da cidade, no sentido do plano alertar para a indução da ocupação ao longo dos "braços de terra firme entre as ressacas". Este elemento é essencial, pois ele limita as áreas de terra firme disponíveis para ocupação, o que tem gerado um intenso processo de valorização do solo urbano ao longo dos eixos de estruturação urbana, principalmente no Eixo Sul.

Também merece destaque o fato do plano ter pensado numa produção do espaço urbano relacionando Macapá e Santana, deste modo duas etapas foram estabelecidas pelo para a expansão urbana: a previsão da 1a fase foi para os 5 anos entre 1979 e 1983 e "deveria, naturalmente, ser condicionada às aferições anuais e a primeira revisão do presente Plano que e recomendada para daqui a cinco anos, ou seja, 1978" (PDDUFJP, 1973, p.23). A segunda fase previa um espaço de tempo para além de 10 anos, pautado em constantes reavaliações e revisões, tendo em vista que a proposta da Fundação João Pinheiro teria um alcance temporal limitado.

Apesar de revelar possibilidades para a expansão urbana ao longo das rodovias de interligação, o plano sugere a proibição de novos loteamentos por cinco anos, ou seja, entre 1973 e 1978, objetivando o adensamento da porção mais central e suas áreas imediatas, segurando, inicialmente, a expansão do perímetro urbano.

O plano é bastante complexo e pensa a cidade, mesmo sem a participação social,

de terrenos urbanos de baixo custo será atendida mediante a ocupação de áreas periféricas urbanizáveis equidistantes das áreas centrais" (PDDUFJP, 1973, p.19). de maneira interessante, chegando a propor inclusive espaços para uma possível conurbação entre as cidades, apontando as três rodovias de interligação como possibilidades para esse processo, que contava com mais uma rodovia de interligação, além das duas anteriormente citadas. A Rodovia de Interligação no 1 , que ligava Macapá a Zona Industrial (foi esta a rodovia citada no PUCMRGB) e tinha, também, a função de atuar como indutora da ocupação da área entre as rodovias Macapá/Santana e Macapá/Fazendinha/Santana, constituindo-se numa terceira opção do trafego Macapá/Santana (PDDUFJP, 1973, p.25).

As relações projetadas para as rodovias de interligação entre Macapá e Santana já indicavam possibilidades de descentralização, conurbação e a formação de núcleos secundários ${ }^{*}$; revelando, portanto, que as contribuições do PDDUFJP foram bastante significativas para se pensar o contexto atual da produção do espaço urbano de Macapá e Santana. Muitas projeções se materializaram com intensidades diferentes ao longo dos eixos de estruturação urbana.

O Plano Diretor de Desenvolvimento Urbano e Ambiental de Macapá (PDDUAM), de 2004, traz uma discussão bem interessante em seu Capítulo III (DA ESTRATÉGIA PARA MELHORIA DA MOBILIDADE/Seções I, II e III), subdivididas em Estratégia para o Território Municipal e Estratégia para a Cidade de Macapá. Nele discutiu-se o sistema de mobilidade intraurbana e da cidade como restante do município, diante da necessidade de uma "maior integração regional,

\footnotetext{
${ }^{8}$ No PUCMRGB havia apontamentos analíticos na direção da formação de subcentros como tentativa de desafo-
gar o centro da cidade na época. Isso é importante do da formação de subcentros como tentativa de desafo-
gar o centro da cidade na época. Isso é importante do ponto de vista da própria organização espacial da cidade.
}

https://periodicos.unifap.br/index.php/estacao Macapá, v. 6, n. 3, p. 111-126, set./dez. 2016 
entre os distritos e a sede e entre o Município de Macapá e as suas áreas de influência, sobretudo o Município de Santana" (PDDUAM, 2004, p.20), isto se daria pela circulação rodoviária e hidroviária, aproveitando as potencialidades hidrográficas locais.

Fazendinha é destacada como foco de necessidade de uma maior integração, pela melhor circulação viária e hidroviária, com o restante da cidade e até mesmo entre os outros bairros, além disso, defendeu-se a garantia universalizada de acessibilidade aos equipamentos urbanos, transportes e outros serviços.

Para a escala do município o PDDUAM define que a melhoria da mobilidade ocorreria, por exemplo, através de parcerias com o governo federal e estadual, em ações das seguintes rodovias: Rodovia BR-156; Rodovia BR-210; Rodovia AP-010; Rodovia AP-070; Rodovia AP-340. Já para a escala da cidade as vias de circulação pensadas como espaços democráticos como a garantia de acessibilidade a pedestres e ciclista, neste recorte é importante destacar que o Plano identifica as rodovias que estruturam três dos quatro eixos propostos neste trabalho: sob a tutela federal, encontra-se a BR-210 e sob a tutela do estado a Rodovia AP-010 (Rodovia Juscelino Kubitschek); Rodovia AP020 (Rodovia Duque de Caxias); Rodovia AP070 (Rodovia do Curiaú) ${ }^{9}$.

Complementa ainda o sistema rodoviário municipal o Terminal Rodoviário de Macapá, sediado no Eixo Norte, e alguns pontos de apoio à cidadania (rodoviários e inter-

\footnotetext{
${ }^{9}$ Estas três rodovias foram definidas como eixos prioritários para a estruturação urbana no PDDUAM, além delas destaca-se também a Rodovia do Pacoval e o seu prolongamento a ser implantado e a Rodovia Norte-Sul, a ser implantada.
}

modais), dentre estes pontos vale destacar o distrito do Coração, comunidade remanescente de quilombola, localizado no Eixo Oeste.

\section{FORMA, FUNÇÃO, ESTRUTURA E PRO- CESSOS NO EIXO SUL DE MACAPÁ}

Num recorte temporal recente, mais precisamente a partir do final da década de 1980, vem ocorrendo um novo olhar para o Eixo Sul, voltado principalmente para o lazer, serviços da educação superior, do turismo e para um uso residencial (Mapa 03). Quanto às atividades de lazer, destaca-se o número significativo de clubes como a ASEEL, SINSEPEAP, SINDESAÚDE, OAB e também um serviço concentrado de motéis ao longo da rodovia JK; os serviços da educação dizem respeito basicamente ao campus Marco Zero da UNIFAP com seus cursos e o status de principal Universidade do Amapá, a EMBRAPA, ao futuro campus da Universidade do Estado do Amapá e ao Instituto Estadual de Pesquisas do Amapá, quanto ao turismo há a presença nesse eixo do estádio Zerão e do monumento Marco Zero do Equador, marcados pela latitude zero, dividindo, simbolicamente, o hemisfério sul e o hemisfério norte, além disso, há o parque de exposição onde é realizado anualmente a Expofeira (feira agropecuária) e, também, o distrito de fazendinha como ponto de encontro da cidade de Macapá, com bares, restaurantes e área pra banho nas margens do rio Amazonas. 
Mapa 03: Novos Produtos Imobiliários do Eixo Sul de Macapá (AP-020).

Map 03: New Real Estate Products of the South Axis of Macapá (AP - 020).

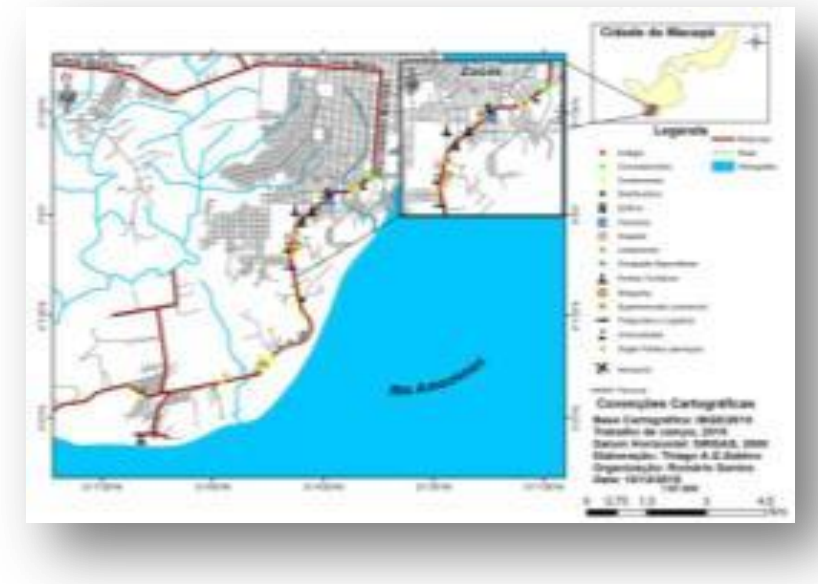

Fonte: Santos (2016).

Mesmo com outros usos, o que tem chamado mais atenção no Eixo Sul é a expansão dos novos produtos imobiliários da habitação, especialmente os condomínios e loteamentos, do comércio e de serviços como o Amapá Garden Shopping. Os loteamentos e condomínios já são bastante significativos neste eixo, conforme mostra o Quadro 02, revelando como a cidade de Macapá tem sido produzida ao longo desse eixo.

Quadro 02: Novos Produtos imobiliários da Habitação do Eixo Sul de Macapá (AP - 010).

Frame 02: New Housing Products of the South Axis of Macapá (AP - 010).

\begin{tabular}{|c|c|c|c|c|c|}
\hline $\begin{array}{l}\text { Empreen- } \\
\text { dimento } \\
\text { (ano de } \\
\text { implanta- } \\
\text { ção) }\end{array}$ & \begin{tabular}{|l|} 
Localização \\
\end{tabular} & Uso & $\begin{array}{l}\text { Ano de } \\
\text { libera- } \\
\text { ção ou } \\
\text { implan- } \\
\text { tação }\end{array}$ & $\begin{array}{c}\text { Forma do } \\
\text { empreen- } \\
\text { dimento } \\
\text { (vertical ou } \\
\text { horizontal) }\end{array}$ & $\begin{array}{c}\text { Descrição do } \\
\text { empreendimento }\end{array}$ \\
\hline $\begin{array}{c}\text { RESIDENCI- } \\
\text { AL SAN } \\
\text { MARINO }\end{array}$ & $\begin{array}{l}\text { Rodovia JK } \\
\text { - Pedrinhas }\end{array}$ & \begin{tabular}{|c|} 
RESI- \\
DENCIAL
\end{tabular} & 1990 & $\begin{array}{c}\text { HORIZON- } \\
\text { TAL } \\
\end{array}$ & $\begin{array}{l}\text { Lançado no ano } \\
\text { de 1990, este é } \\
\text { um dos novos } \\
\text { produtos imobiliá } \\
\text {-rios mais antigos } \\
\text { do AUMS. Possui } \\
42 \text { lotes e foi apro } \\
\text {-vado na forma de } \\
\text { loteamento, mes- } \\
\text { mo funcionando } \\
\text { como condomínio } \\
\text { na prática. }\end{array}$ \\
\hline
\end{tabular}

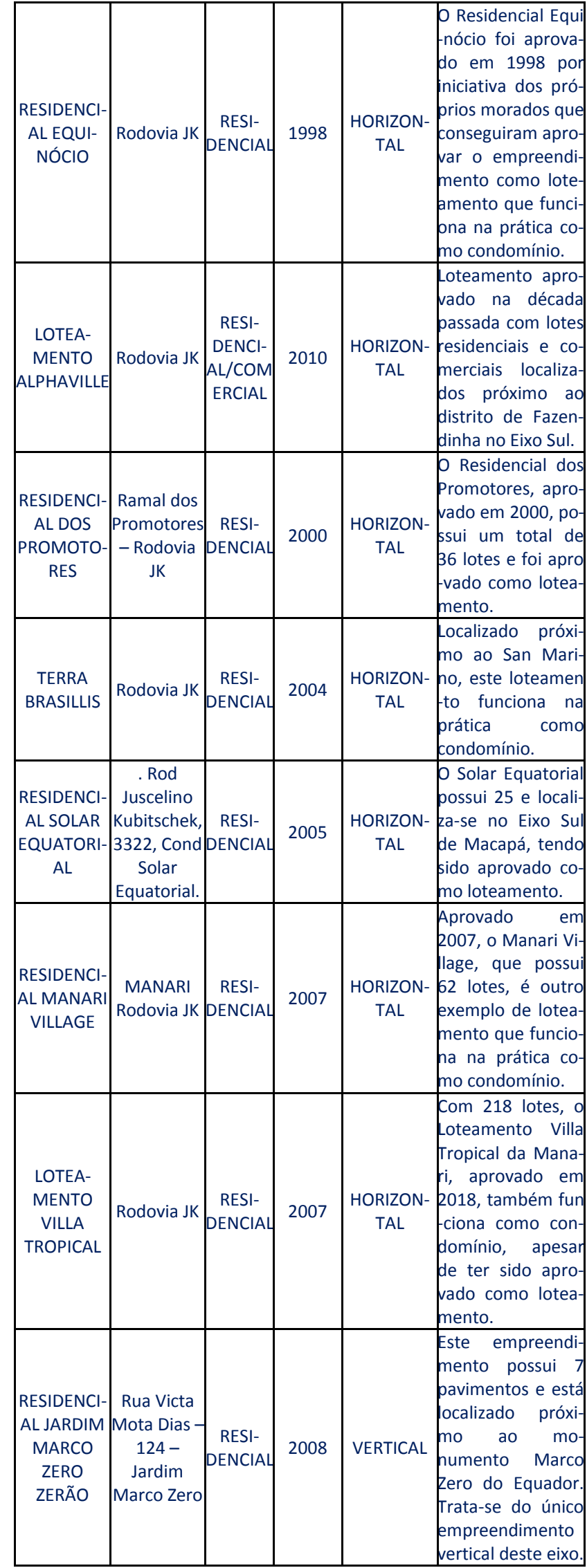




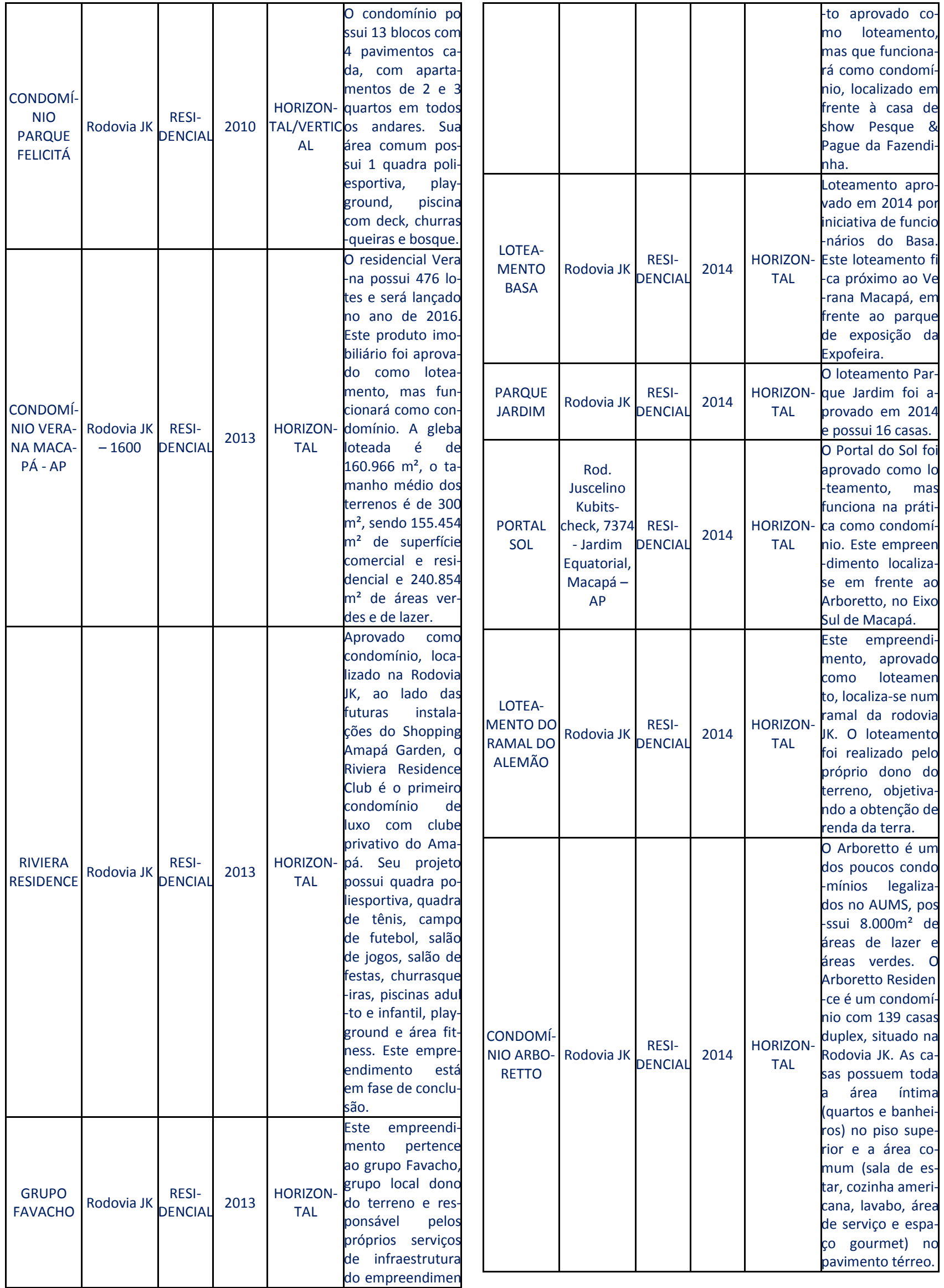




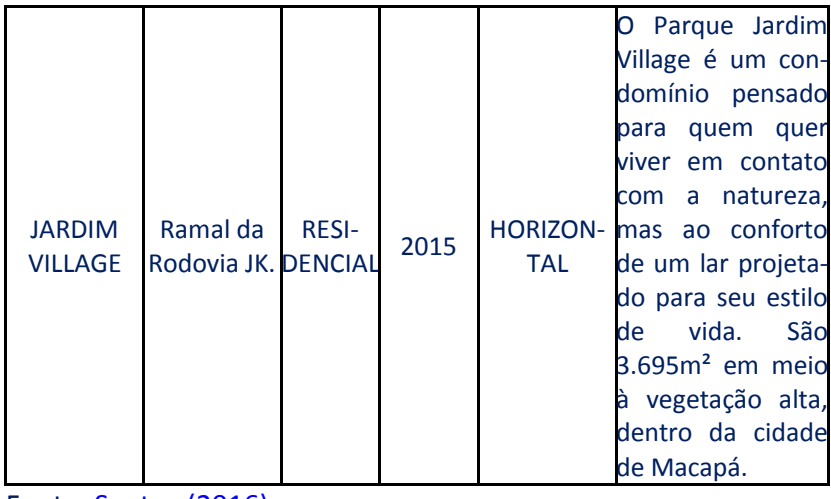

Fonte: Santos (2016).

O padrão dos novos produtos imobiliários deste eixo revela um público-alvo com relativo poder aquisitivo, já que em geral o preço dos lotes não é tão baixo, comparando o preço dos lotes por eixo e/ou centro urbano como em outras partes da cidade, mesmo se tratando de áreas mais periféricas, reforçando a tese de que, em termos teóricos, a relação entre centro e periferia tem sido reformulada, devido à própria refuncionalização da periferia. Portanto é equivocada a associação entre periferia e pobreza.

Também vale reforçar a incorporação de áreas de ressaca, conforme mencionado antes, por alguns condomínios a partir de lobs articulados com o poder público. Isso ocorre, não apenas no condomínio Verana Macapá, mas também no condomínio situado em frente ao loteamento Alphaville nas imediações da casa de show "Pesque \& Pague da Fazendinha", conforme indicam as Imagens 01, 02, $\underline{03}$.
Imagem 01: Área de Ressaca incorporada em condomínio horizontal no Eixo Sul de Macapá

Image 01: Hangover area incorporated in a horizontal condominium in the South Axis of Macapá

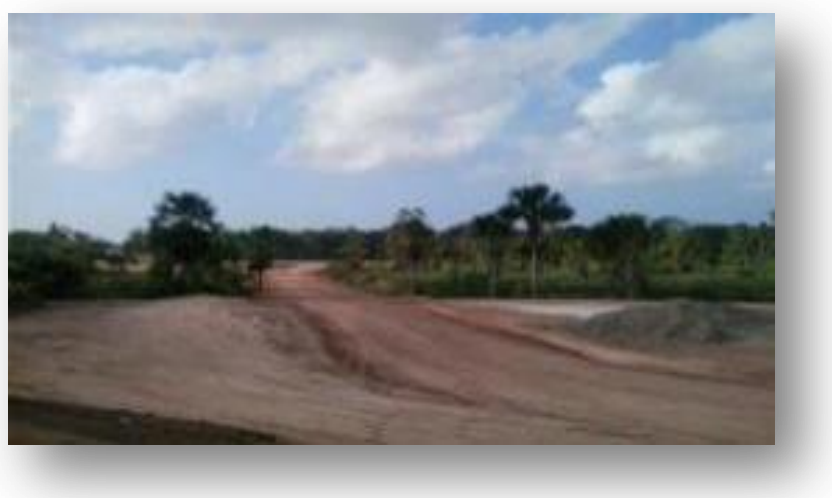

Fonte: $\underline{\text { Santos, } 2016}$

Imagem 02: Drenagem de águas pluviais em área de Ressaca incorporada por condomínio horizontal no Eixo Sul de Macapá Image 02: Drainage of rainwater in a Hangover area incorporated by a horizontall condominium in the South Axis of Macapá

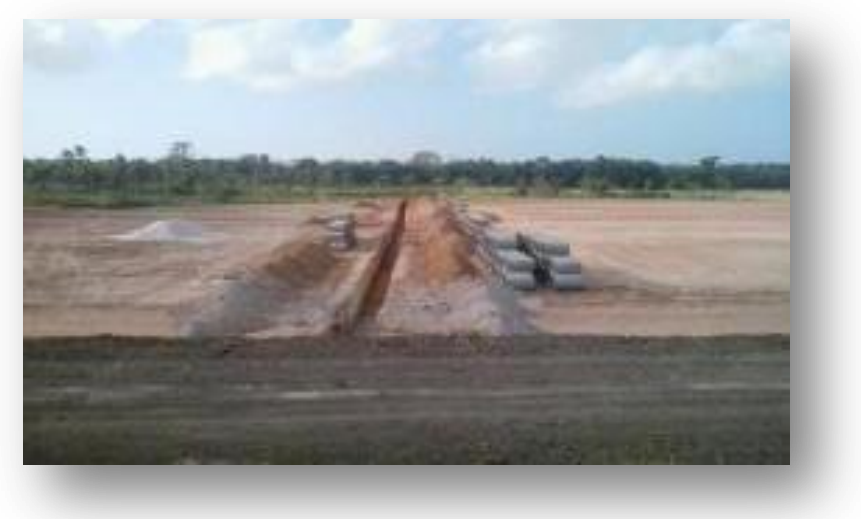

Fonte: Santos, 2016

Imagem 03: Vista da Rodovia JK - Eixo Sul, motivada pelo alagamento da área de ressaca no condomínio Verana Macapá Image 03: View of Highway JK - South Axis, motivated by the flooding ofthe hangover area in the Verana Macapá Condominium

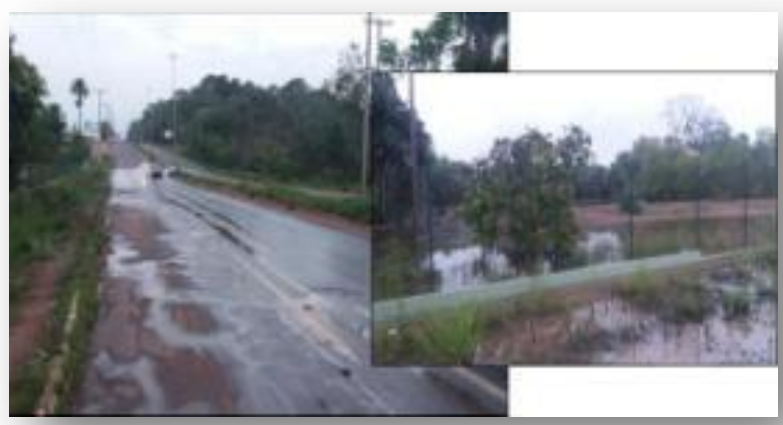


Fonte: $\underline{\text { Santos, } 2016}$

As Imagens 01 e 02 demonstram o quanto as áreas de ressaca têm sido incorporadas nessa lógica imobiliária em Macapá e Santana, com a participação inclusive do poder público, pois há leis específicas que definem essa porção da cidade de Macapá como Área de Proteção Ambienta - APA da Fazendinha, ficando vedada, portanto, qualquer tipo de uso referente a ocupação humana. Já a Imagem 03 revela os riscos ambientais decorrentes do aterramento das áreas de ressacas.

Este é o quadro atual da produção do espaço urbano de Macapá no seu Eixo Sul, marcada pela expansão de novos produtos imobiliários muito mais numa perspectiva horizontal, assim como nos outros eixos, destoando apenas o residencial Parque Felicitá e o Amapá Garden Shopping que possuem alguns poucos andares em suas estruturas, no caso do residencial a estrutura é semelhante aos blocos dos empreendimentos do Programa Minha Casa Minha Vida PMCMV, do Governo Federal (Imagem 04).

Imagem 04: Bloco residencial do Parque Felicitá Image 04: Residencial block of Felicitá Park

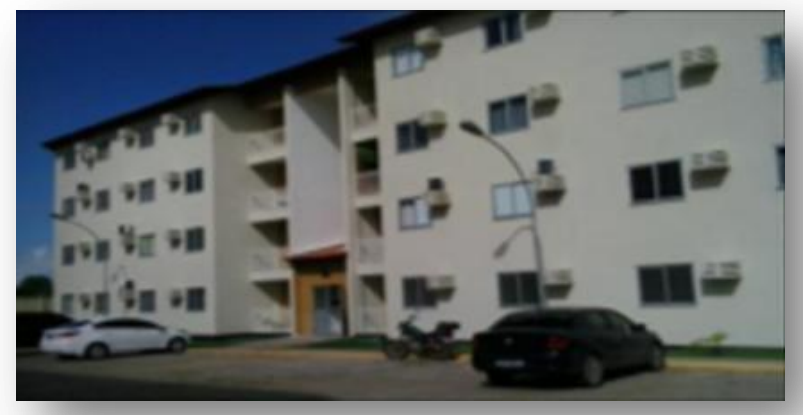

Fonte: Trabalho de campo, 2015

$\mathrm{Na}$ Imagem 04 visualiza-se um dos blocos do Residencial Parque Felicitá da Vex. Este é um dos poucos produtos imobiliários da habitação que funcionam na prática exata- mente como foram aprovados no cartório de imóveis, ou seja, aprovado como condomínio e funciona como tal. Além do Parque Felicitá, em todo o AUMS só há mais três condomínios legais: Riviera e Arboretto também no Eixo Sul (Vex Construções Amapá) e o Vila Bella no Eixo Oeste (SPE Brasília), todos possuem um elevado custo, visto que este caráter legal agrega valor ao lote/casa, por isso podem ser compreendidos como verdadeiros enclaves fortifica$\operatorname{dos}^{\underline{10}}$ (CALDEIRA, 2000).

O Loteamento Horizontal Fechado constitui em prática ilegal segundo a legislação vigente $^{\underline{11}}$ e forja a cidade ilegal, pois não deve haver muros nos empreendimentos aprovados como loteamentos. Nestes termos, o Residencial Verana (Imagem 05) da Cipasa e os Loteamentos da empresa Manari no Eixo Sul, são exemplos cabais desta prática, pois constituem-se em empreendimentos ilegais, que se apropriam inclusive de áreas de ressacas, mesmo que liberadas pelo Estado. 
Imagem 05: Loteamento Verana Macapá

Image 05: Allotment Verana Macapá

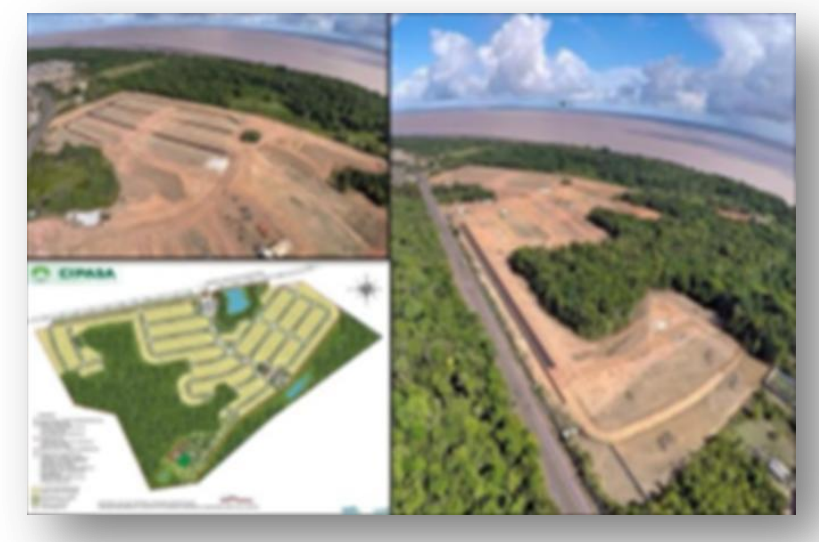

Fonte: Santos, 2016

O avanço da dinâmica imobiliária não se restringe aos novos produtos da habitação, pois novas centralidades intraurbanas são geradas, como nas atividades do setor de comércio e serviços, cuja expressão maior no Eixo Sul corresponde ao Amapá Garden Shopping (Figura 01), reproduz estrutura arquitetônica e de serviços consagradas em grandes centros metropolitanos (AMARAL, 2010).

Figura 01: Vista horizontal do Amapá Garden Shopping. Figure 01: Horizontal view of Amapá Garden Shopping.

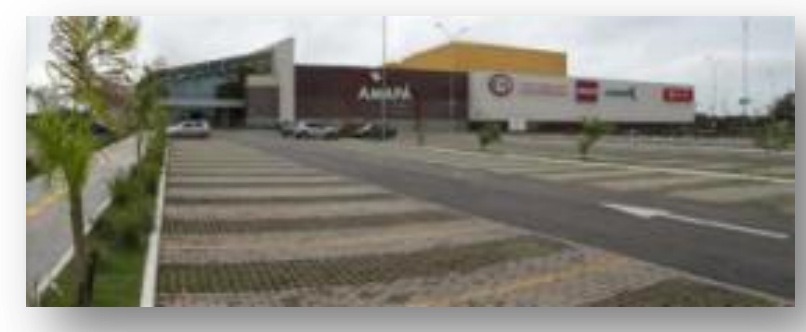

Fonte: amapagarden.shopping.com.br

O Garden, como é conhecido em Macapá e Santana, possui localização estratégica, pois atende a população de Macapá e também a clientela que se desloca de Santana, além da população que residirá nos loteamentos e condomínios em construção no
Eixo Sul. Este shopping é resultado de uma parceria entre a CBL \& Associates Properties em parceria com a Tecno Realty de Minas Gerais, além do grupo SEAMA, recentemente comprado pelo grupo Estácio, e mais o grupo Bento Pereira. A área deste empreendimento é de $70.000 \mathrm{~m}^{2}$, com quase $24.000 \mathrm{~m}^{2}$ de área bruta locável, com 157 lojas, 4 âncoras, 1 supermercado, 5 salas de cinema multiplex, 5 megalojas, 133 lojas-satélite e 14 lojas de alimentação, sendo 2 restaurantes, além de 1.500 vagas para carros (AMARAL, 2010).

\section{CONSIDERAÇÕES FINAIS}

Têm-se verificado o crescimento da ocupação ao longo dos eixos rodoviários presentes na estruturação espacial de Macapá e Santana, acompanhando a tendência de transformação de rodovias em vias de circulação intraurbana de outras regiões do país, onde há conurbação, conforme destacado anteriormente.

A difusão dos novos produtos imobiliários tem acentuado a conurbação entre Macapá e Santana, além de revelar uma produção mais periférica da cidade, não apenas nos termos tradicionais onde a periferia é entendida como sinônimo de precariedade, mas sim cercada de uma valorização espacial significativa, a partir de exemplos como o Verana Macapá, cujo lote mais barato custa 300 mil reais. Desta forma, a produção do espaço urbano do Eixo Sul de Macapá vem acontecendo nos termos da renda da terra, portanto transformando terra rural (como destacado nos planos diretores urbanos) em terra urbana, considerando as dinâmicas socioespaciais que se processam nesses espaços.

Também é importante considerar a base 
natural (a dimensão física do espaço) como elemento de valorização espacial, pois, em geral, os lotes do Eixo Sul de Macapá são bem mais caros que nos outros eixos, isso porque a faixa de terra loteável é bem menor, considerando que de um lado há o rio Amazonas e do outro as ressacas.

Outro ponto muito importante é a inversão que vem ocorrendo em relação à ocupação das áreas de ressaca, que tradicionalmente foram sendo ocupadas pelos grupos sociais excluídos, onde impera uma face com sérios problemas urbanos como déficit habitacional, precariedade ou ausência de saneamento urbano, violência dentre outros (SANTOS, 2016). Mas que agora começa a ser incorporada, numa dualidade institucional, por população de considerável faixa de renda nos condomínios e loteamentos espalhados pelo Eixo Sul de Macapá, por exemplo.

Deve-se destacar também, que acompanhado dessa expansão imobiliárias vem a segregação socioespacial, problemas de acessibilidade, surgimento de novas centralidades intraurbanas, por isso vale reforçar aqui a necessidade cada vez maior de um planejamento urbano integrado entre as duas cidades, considerando, portanto, a existência do Aglomerado Urbano de Macapá e Santana e a relevância socioespacial dos processos verificado em seus diferentes recortes, como no Eixo Sul.

\section{REFERÊNCIAS}

AMARAL, M. D. B. Dinâmicas econômicas e transformações espaciais: a metrópole de Belém e as cidades médias da Amazônia Oriental - Marabá (PA) e Macapá (AP). 347 f. Tese (Doutorado em Geografia) - Faculdade de Filosofia Letras e Ciências Huma- nas, Universidade de São Paulo, São Paulo, SP, Brasil, 2010.

BRASIL. Lei no 9785, de 29 de janeiro de 1999. Dispõe sobre o parcelamento do solo urbano. Disponível em: <www.lei.adv.br/97 85-99.htm >. Acesso em: 23 jul. 2015.

CALDEIRA, T. P. R. Cidade de muros: crime, segregação e cidadania em São Paulo. São Paulo: Ed. 34/Edusp, 2000.

MOURA, G. G. Condomínios horizontais/loteamentos fechados e a vizinhança (in)desejada: um estudo em Uberlândia/ MG. Tese - Universidade Federal de Uberlândia. Instituto de Geografia, Programa de Pós-Graduação em Geografia, 2008.

Plano Urbanístico da Cidade de Macapá. Relatório da Grumbilf do Brasil. São Paulo. 1960.

Plano de Ação Imediata de Macapá. Governo do Território Federal do Amapá. Biblioteca da AS. Técnica - 1971.

Plano Diretor de Desenvolvimento Urbano - PDDU. Fundação João Pinheiro, Macapá, 1973.

Plano Diretor de Desenvolvimento Urbano e Ambiental de Macapá. Macapá, P. M. M. - SEMPLA, IBAM. 2004.

SANTOS, E. R. C. Configuração Geográfica na Fronteira Setentrional Amazônica: os grandes projetos do Amapá-Brasil. In: I Simpósio Internacional de Geografia Política e Território Transfronteiriços, 2011, Foz do Iguaçu. Geografia Política Território e Poder, 2011.

Amazônia Setentrional Amapaense: do "mundo" das águas às florestas protegidas. Tese (Doutorado), FCT-UNESP, Presidente Prudente, São Paulo, SP, Brasil, 2012.

SANTOS, R. V. O Aglomerado Urbano Macapá-Santana: a cidade média da Amazônia Setentrional Amapaense. Anais XIV Simpó- 
sio Nacional de Geografia Urbana: Perspectivas e Abordagens da Geografia Urbana no Século XXI. Realizado de 8 a 12 de setembro de 2015. Fortaleza - CE, 2015.

- (RE)Estruturação e formação do aglomerado urbano de Macapá e Santana na Amazônia Setentrional Amapaense. Dissertação (Mestrado em Desenvolvimento Regional) - Universidade Federal do Amapá, Macapá, 2016. 201 f. :il.

TAKIYAMA, L. R. et al. Projeto zoneamento ecológico econômico urbano das áreas de ressacas de Macapá e Santana, Estado do Amapá: relatório técnico final. /Luis Roberto Takiyama. Macapá: IEPA, 2012.

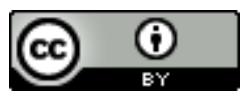

License information: This is an openaccess article distributed under the terms of the Creative Commons Attribution License, which permits unrestricted use, distribution, and reproduction in any medium, provided the original work is properly cited.

Artigo recebido em 03 de maio de 2016.

Avaliado em 23 de novembro de 2016.

Aceito em 13 de dezembro de 2016.

Publicado em 28 de março de 2017.

Como citar este artigo (ABNT):

SANTOS, Romário Valente; BARROS, Elcimar de Souza. Produção do espaço no eixo sul do aglomerado urbano de Macapá e Santana na Amazônia setentrional amapaense. Estação Científica (UNIFAP), Macapá, v. 6, n. 3, p. 111-126, set./dez. 2016. 